\title{
Consciousness and conscience
}

\section{Stuart Sutherland}

Consciousness Regained. By Nicholas Humphrey.

Oxford University Press: 1983. Pp.222. £12.95, \$19.95.

MANY of the world's best minds have wrestled with the problem of consciousness; so for that matter have many of the worst. In Consciousness Regained, a collection of essays most of which have been published elsewhere, Dr Nicholas Humphrey joins the throng. He claims, unexceptionally, that since consciousness has presumably evolved, it must have a function, which is, he suggests, to enhance social interaction. He reaches this conclusion in two steps, the first of which concerns the intellect rather than consciousness.

According to Humphrey, the intellect in man and many other primates has been developed to a point far beyond that needed to deal with the material environment. He argues that chimpanzees and gorillas, who have invented a technology for subsisting, have less need for intelligence than do less technologically orientated primates. Merely by watching another member of its group, a chimpanzee can learn to poke a stick into a termites' nest and draw it out covered with a tasty feast. The individual animal does not have to use creative intelligence. The argument ignores the question of how the technique was invented in the first place: even if it was learned by trial and error, poking sticks into nests is a creative act and the chimpanzee has to make the connection between it and the resulting mouthful of termites. Moreover, although high intelligence might not be needed for day-to-day living, chimpanzees and gorillas must sometimes be subjected to novel and dangerous events which they can survive only by the use of intelligence. In the case of man, the argument is even weaker since his physical defences and resources are less and his survival - often under very adverse external conditions - depends entirely on his ability to manipulate the physical world by the use of intelligence. Although it is impossible to assess how far the intelligence of a given species evolved through pressure to cope with the physical world, there may be some truth in Humphrey's ingenious alternative - that in man and some other primates it evolved in order to help the individual deal with other members of the species.

There is, however, a big leap from this conclusion to the next step in his argument: he maintains that consciousness itself arose in order to help man (and possibly some other primates) understand the behaviour of others. Consciousness provides a model of the way in which people's own minds work - a model of their emotions, motives, thoughts and sensations: in so far as different minds are similar this model provides a basis for understanding others. There is, unfortunately, an obvious fallacy in the argument. The brain could represent the processes underlying motives, thinking and so on and could use this representation as a model for others' behaviour and the forces underlying it without the representation appearing in consciousness. Indeed,

IMAGE
UNAVAILABLE
FOR
COPYRIGHT
REASONS

Nicholas Humphrey - " "fun to read".

Humphrey himself argues elsewhere that the brain contains a representation of the position of the parts of the body, but that this representation does not appear in consciousness. It is easy to invent functions that consciousness might subserve: what is difficult and has never yet been achieved is to show that they can be subserved only by consciousness.

There are three lesser problems with Humphrey's thesis. First, he does not sufficiently distinguish between consciousness and self-awareness. It is hard to believe that species other than primates lack consciousness, though they may lack self-awareness. Second, it is simply not true that in most of their dealings with others people use a conscious model either of their own behaviour or of that of others. People normally interact spontaneously and with little or no conscious thought. It is only when social interactions go wrong that they start to think consciously about them often with unfortunate consequences. Third, if the reason why people are selfaware is to enable them to understand others, it is curious that self-knowledge should be so fallible. People's motives are often more transparent to others than to themselves.

For the rest, Humphrey is always stimulating and fun to read, though by its nature most of his book is rather bitty. He develops the far from novel idea that the reason why people engage in activities which seem to have no direct relevance to survival is that the activities provide novel experiences in terms of which people can better understand others. Some examples are play, initiation ceremonies, dreaming, keeping pets, watching dramatic performances and the manipulation of children by parents - particularly gratuitous cruelty. It is hard to accept that the function of such cruelty is to teach a child what it feels like to be unfairly treated, particularly as what evidence there is suggests that maltreated children tend to become poorly adjusted adults.

Another perennial problem that Humphrey tackles is that of the value of art. He argues that in classifying objects in the natural world, people look for sets whose members are similar in some respect to all the others, but differ in some way from the members of other sets. Much art (and, he might have added, almost all music) consists of variations on a theme and hence it teaches the viewer to spot similarities and differences and gives him practice in the task of classification. This is an ingenious account of the intellectual content of art, but leaves out its emotional force.

The book ends with a series of disconnected essays and book reviews, which are lively, but lightweight. Humphrey rightly and suavely demolishes the pretensions of such self-appointed gurus as Douglas Hofstadter and Gregory Bateson, and he provides a piece of impassioned rhetoric on nuclear war, in which he appeals to everyone to go out and stop it. He declaims "I have not heard of one good reason for not halting [nuclear armaments] tomorrow". Unfortunately he is so carried away by his own rhetoric that he omits to tell both the man in the street and the politicians exactly what it is they should do to prevent nuclear war.

Humphrey writes with elegance and force, and although he sometimes fails to follow his ideas through, they are always stimulating. Even the reader who disagrees with his arguments will derive pleasure from working out for himself why they are wrong.

Stuart Sutherland is Director of the Centre for Research on Perception and Cognition at the University of Sussex. 